\title{
Preparation of organotypic brain slice cultures for the study
}

\section{of Alzheimer's disease [version 1; peer review: 3 approved]}

\author{
Cara L. Croft (iD1,2, Wendy Noble (iD)2 \\ ${ }^{1}$ Center for Translational Research in Neurodegenerative Disease, Department of Neuroscience, University of Florida, Gainesville, \\ $\mathrm{FL}, 32610$, USA \\ ${ }^{2}$ Department of Basic and Clinical Neuroscience, Maurice Wohl Clinical Neuroscience Institute, Institute of Psychiatry, Psychology \& \\ Neuroscience, King's College London, London, SE5 9RX, UK
}

V1 First published: 15 May 2018, 7:592
https://doi.org/10.12688/f1000research.14500.1

Latest published: 27 Jun 2018, 7:592

https://doi.org/10.12688/f1000research.14500.2

\section{Open Peer Review}

Approval Status

123

version 2

(revision)

27 Jun 2018

version 1

15 May 2018

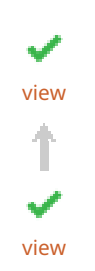

$\ldots$

............

1. Claire S. Durrant ID, University of

Cambridge, Cambridge, UK

2. Christian Humpel, Medical University of Innsbruck, Innsbruck, Austria

3. Susan C. Barnett iD, University of Glasgow, Glasgow, UK

Any reports and responses or comments on the article can be found at the end of the article. 
genes may provide a valid and sensitive replacement for in vivo studies that do not involve behavioural analysis.

\section{Keywords}

Organotypic brain slice culture, neurodegeneration, amyloid- $\beta$, tau,

Alzheimer's disease, transgenic mice, reduction

\section{NC \\ $3 R^{s}$}

This article is included in the NC3Rs gateway.

Corresponding authors: Cara L. Croft (cara.croft@ufl.edu), Wendy Noble (wendy.noble@kcl.ac.uk)

Author roles: Croft CL: Conceptualization, Formal Analysis, Investigation, Methodology, Validation, Visualization, Writing - Original Draft Preparation, Writing - Review \& Editing; Noble W: Conceptualization, Data Curation, Formal Analysis, Funding Acquisition, Methodology, Project Administration, Resources, Supervision, Visualization, Writing - Original Draft Preparation, Writing - Review \& Editing

Competing interests: No competing interests were disclosed.

Grant information: This work was supported by funding from the National Centre for Replacement, Refinement and Reduction of Animals in Research (NC/K500343/1 to WN) and the Biotechnology and Biological Sciences Research Committee (BB/L502601/1 to WN).

Copyright: @ 2018 Croft CL and Noble W. This is an open access article distributed under the terms of the Creative Commons Attribution License, which permits unrestricted use, distribution, and reproduction in any medium, provided the original work is properly cited. Data associated with the article are available under the terms of the Creative Commons Zero "No rights reserved" data waiver (CC0 1.0 Public domain dedication).

How to cite this article: Croft CL and Noble W. Preparation of organotypic brain slice cultures for the study of Alzheimer's disease [version 1; peer review: 3 approved] F1000Research 2018, 7:592 https://doi.org/10.12688/f1000research.14500.1

First published: 15 May 2018, 7:592 https://doi.org/10.12688/f1000research.14500.1 
Research highlights

\section{Scientific benefits:}

- Neurodegeneration in AD is progressive and agedependent and therefore many experiments rely upon animals developing a moderate to severe phenotype prior to assessment of disease parameters

- Aging slices in a culture dish obviates this requirement, as well as providing an in vitro system in which all neural cell types are present, and functional and anatomical connectivity is retained

\section{Rs benefits:}

- Brain slice cultures can be used as an alternative to some in vivo experiments thereby reducing the numbers of animals required for such studies

- Disease phenotypes are accelerated in brain slice culture models so equivalent data can be obtained from neonatal mice in 1 month of in vitro experiments rather than 12 months of aging in vivo from fewer total mice

- 36 brain slices can be cultured from a single mouse brain, so studies can be refined as it is possible to assess several parameters or disease-modifying agents in a single brain thereby minimising biological variation

\section{Practical benefits:}

- This model is considerably more time and cost effective when compared to in vivo studies

\section{Current applications:}

- The 3xTg-AD slice culture model is suitable for biochemical and immunohistochemical research into Alzheimer's disease and related tauopathies

\section{Potential applications:}

- Long-term organotypic brain slice cultures have the potential for use in all aspects of neuroscience

- Cultures from other tissues will have utility for many other fields of biological and biomedical research

\section{Introduction}

Alzheimer's disease (AD), the most common cause of dementia, currently affects around 35 million people worldwide and carries huge societal and economical costs. AD is a multifactorial disease with two major pathological hallmarks; extracellular plaques composed of $\beta$-amyloid $(A \beta)$ and intracellular neurofibrillary tangles containing aggregated posttranslationally modified tau. The only available treatments for $\mathrm{AD}$ target the symptoms of disease, but not disease course. Intensive research efforts are ongoing to better understand the biological causes of disease so that effective disease-modifying therapies can be developed.

Perhaps the most accepted models for $\mathrm{AD}$ research are transgenic rodents that express wild-type or mutant human $\mathrm{AD}$-associated genes and recapitulate key molecular phenotypes of AD. Mice are generally one of the best accepted animal models in neuroscience research since there is significant homology between the human and mouse genome, mice have a relatively short life span, well-defined genetic backgrounds, are amenable to further genetic manipulations, enable assessment of changes in behaviour, cognition, brain biochemistry and physiology during disease progression, and a battery of wellcharacterised tasks are available to study behaviour and cognition ${ }^{1}$.

Our calculations, based on a PubMed search using the terms "Alzheimer's + transgenic + mouse" and assuming an average of 30 mice for each of the 700 papers published, suggest that over 20,000 transgenic mice were used in AD research in 2017. Due to the age-related neurodegenerative nature of the disease, this research often involves aging several cohorts of mice to observe disease progression. Allowing mice expressing ADrelated genes to reach the terminal stages can result in severe phenotypes, and some studies are coupled with invasive procedures such as advanced live imaging or collection of interstitial or cerebrospinal fluids.

Alternatives to in vivo $\mathrm{AD}$ research in mammalian systems include rodent and human cell lines manipulated to express genes of interest, however these can be criticised for lacking key features of differentiated post-mitotic neurons and can be prone to artefacts resulting from protein over-expression. Dissociated neural cell cultures are commonly used as a readily tractable model in which pathways of interest can be manipulated, however even co-culture systems do not completely replicate the complex connections between different neural cell types and the brain vasculature, and they cannot model the synaptic and anatomical connectivity of mammalian brain. The latter is also true for neural cells derived from human induced pluripotent stem cells (iPSCs). Recent reports using iPSC-derived neurons also highlights the extensive time in culture required before even subtle disease relevant changes are observed in these human neural cells ${ }^{2}$.

Organotypic brain slice cultures are a well-established technique. Slice cultures maintain a three-dimensional organisation with the preservation of cytoarchitecture and cell populations, and are an accessible system lending their application to electrophysiology, morphology and biochemical analyses ${ }^{3,4}$. The interfaceslice culture method established by Stoppini and colleagues in $1991^{5}$ is the most common method to culture brain sections ex vivo. This relatively simple method cultures brain tissue explants from neonatal mice/rats on a porous membrane insert that acts as an interface between the humidified incubator atmosphere and the culture medium that provides nutrition ${ }^{5}$. Cultures can be maintained for several weeks in culture after explant and continue to develop and mature once plated ${ }^{6,7}$. Importantly, slice cultures are prepared from neonatal mice precluding aging transgenic mice to a stage when they develop a detrimental phenotype. In addition, 36 slices containing the cortex and hippocampus can be prepared from one postnatal mouse brain allowing multiple variables to be tested or manipulated in tissue from the same mice, thereby considerably reducing the number of mice required as well as minimising experimental variation. 
$\mathrm{AD}$ researchers are beginning to embrace organotypic brain slice culture models, with recent papers describing AD-relevant changes in slice cultures prepared from mice that overexpress amyloid precursor protein or are seeded with $A \beta$, which show some accumulation of $A \beta$ and synaptic alterations ${ }^{8-10}$. Others have shown that slice cultures prepared from mice that overexpress human tau can accumulate phosphorylated and some sarkosylinsoluble $\operatorname{tau}^{10,11}$. We recently demonstrated that slice cultures prepared from $3 \times \mathrm{Tg}-\mathrm{AD}$ mice ${ }^{12}$ overproduce $\mathrm{A} \beta$, accumulate somatodendritic and synaptic phosphorylated tau at an accelerated rate compared to $3 \mathrm{xTg}-\mathrm{AD}$ mice ${ }^{13}$, allowing study of $\mathrm{A} \beta$-tau interactions and $\mathrm{AD}$ disease pathways ex vivo.

The utility of slice cultures for drug discovery efforts has previously been reviewed ${ }^{14}$, and we have validated $3 \times T$ T-AD slice cultures for this purpose by showing that the effects of disease-modifying compounds observed in vivo can be recapitulated in slice culture ${ }^{15}$. We also identified novel targets for compounds, further demonstrating the usefulness of slice cultures for therapeutic development. In this paper, we provide detailed methods for the preparation of organotypic brain slice cultures for the study of $\mathrm{AD}$ and we discuss the advantages of this model system in terms of the 3Rs in AD research, most specifically in reducing mouse numbers. We believe that this model system will be of most benefit to researchers in the neurodegeneration field, who are either focussed on understanding the biological mechanisms underpinning disease or who aim to screen and test the efficacy of novel disease-modifying therapeutics.

\section{Methods overview}

Animals

3xTg-AD mice were obtained under a material transfer agreement from Professor Frank LaFerla (University of California Irvine, USA) and maintained as a breeding colony at King's College London. 3xTg-AD mice express mutant human PS1 (M146V), APP (Swe, K670N, M671L) and tau (P301L) transgenes ${ }^{12}$. Wild-type (WT) mice of an identical background strain (F2 hybrid: C57BL/6J and 129S1/SvImJ) were maintained as background controls. All housing and experimental procedures were carried out in compliance with the local ethical review panel of King's College London under a UK Home Office project licence held in accordance with the Animals (Scientific Procedures) Act 1986 and the European Directive 2010/63/ EU. Male and female mice were used in this study. After weaning, mice were housed in single sex groups in standard $40 \mathrm{x}$ $25 \times \times 12 \mathrm{~cm}$ plastic cages. Bedding consisted of kiln dried aspen shavings and paper sizzle nest material (Datesand Ltd, Manchester, UK). Water and food were available (Picolab rodent diet 20; \#5053; Lab Diet, St Louis, MO) ad libitum. Animals were housed at $19-22^{\circ} \mathrm{C}$, humidity $55 \%, 12 \mathrm{~h}: 12 \mathrm{~h}$ light: dark cycle with lights on at 07:30. Cages were cleaned once every two weeks, with mice handled by the tail by experienced animal care staff to transfer them between cages.

\section{Slice culture preparation}

Organotypic brain slice cultures were prepared from postnatal day $8-93 \times T g-\mathrm{AD}^{16,17}$ and background control wild-type mice as previously described ${ }^{11}$. Briefly, pups were culled by decapitation in accordance with the UK Animals in Scientific Procedures Act (1986). Brains from pups were bisected into hemi-brains by a single cut along the midline. The cerebellum, thalamus and brainstem were removed and discarded to leave the cortex, hippocampus and connecting areas. These were kept in ice-cold dissection buffer $\left(1.25 \mathrm{mM} \mathrm{KH}_{2} \mathrm{PO}_{4} \mathrm{pH} 7.4,124 \mathrm{mM}\right.$ $\mathrm{NaCl}, 3 \mathrm{mM} \mathrm{KCl}, 8.19 \mathrm{mM} \mathrm{MgSO}, 2.65 \mathrm{mM} \mathrm{CaCl}, 3.5 \mathrm{mM}$ $\mathrm{NaHCO}_{3}, 10 \mathrm{mM}$ glucose, $2 \mathrm{mM}$ ascorbic acid, $39.4 \mu \mathrm{M}$ ATP in ultrapure $\mathrm{H} 2 \mathrm{O}$, sterile filtered $(0.2 \mu \mathrm{m})$ ) with constant oxygenation throughout the preparation procedure. $350 \mu \mathrm{m}$ coronal slices were cut using a McIlwain Tissue Chopper (Stoelting Europe, Ireland). Eighteen slices from each hemi-brain were collected and 3 consecutive slices per well were positioned on interface-style Millicell culture inserts (Millipore (UK) Ltd.) in 6 well culture plates (ThermoFisher Scientific, UK) containing $1 \mathrm{~mL}$ of sterile slice culture medium (Basal medium eagle (BME), 26.6 mM HEPES, pH 7.1, $19.3 \mathrm{mM} \mathrm{NaCl}, 5 \mathrm{mM}$ $\mathrm{NaHCO}_{3}, 511 \mu \mathrm{M}$ ascorbic acid, $40 \mathrm{mM}$ glucose, $2.7 \mathrm{mM}$ $\mathrm{CaCl}_{2}, 2.5 \mathrm{mM} \mathrm{MgSO}$, $1 \%$ (v/v) GlutaMAX (Life Technologies, Paisley, UK), $0.033 \%$ (v/v) insulin, $0.5 \%$ (v/v) penicillin/ streptomycin (Life Technologies), in ultrapure $\mathrm{H}_{2} \mathrm{O}$, sterile filtered $(0.2 \mu \mathrm{m})$, plus $25 \%(\mathrm{v} / \mathrm{v})$ heat inactivated horse serum (ThermoFisher, UK). Three hours after plating, the culture medium was removed by aspiration and replaced with $1 \mathrm{~mL}$ of pre-warmed fresh sterile culture medium. Brain slices were incubated at $37^{\circ} \mathrm{C}$ and the culture medium was changed from the bottom of each well every 2 to 3 days. Slices are maintained for a minimum of 14 days in vitro prior to treatment/harvesting.

\section{Sample preparation and analysis}

Slice cultures can be pharmacologically or genetically modified using a number of methodologies. These methods are out of the scope of this publication but have previously been published by ourselves and others (for example, 8-11,13,15).

Organotypic brain slice cultures can be fixed on their membrane inserts in 4\% PFA for $4 \mathrm{~h}$ and stained according to Croft et al. ${ }^{13}$. In brief, slice cultures are cut whilst still on their membranes and then treated as free-floating sections. Slice cultures are permeabilised for $18 \mathrm{~h}$ in $0.5 \%$ Triton $\mathrm{X}-100$ at $4{ }^{\circ} \mathrm{C}$ and then blocked in $20 \%$ bovine serum albumin (BSA) for $4 \mathrm{~h}$ at RT. Slice cultures are incubated with primary antibodies overnight at $4^{\circ} \mathrm{C}$ in $5 \%$ BSA, washed and then incubated with fluorophorecoupled secondary antibodies for $4 \mathrm{~h}$ at ambient temperature. Slice cultures are washed a final time before mounting on slides with fluorescent mounting medium (Dako Ltd., Ely, UK) prior to imaging.

Alternatively, tissue can be lysed for subcellular fractionation and/or biochemical analysis as described by us and others ${ }^{9-11,13,15}$. To prepare lysates for immunoblotting, slice culture medium is aspirated and slices washed once with ice-cold PBS. Slices are collected via scraping into ice-cold PBS. Cellular matter is pelleted by centrifugation at 7,000 $\mathrm{g}$ (av) for 30 seconds at ambient temperature. The supernatant is discarded and tissue pellets lysed in $100 \mu \mathrm{L}$ ice-cold extra strong lysis buffer $(10 \mathrm{mM}$ Tris- $\mathrm{HCl} \quad(\mathrm{pH} 7.5), 0.5 \% \quad(\mathrm{w} / \mathrm{v})$ sodium dodecyl sulphate (SDS), $20 \mathrm{mM}$ sodium deoxycholate, 1\% (v/v) Triton-X-100, 
$75 \mathrm{mM}$ sodium chloride, $10 \mathrm{mM}$ ethylenediaminetetraacetic acid (EDTA), $2 \mathrm{mM}$ sodium orthovanadate, $1.25 \mathrm{mM}$ sodium fluoride) and protease inhibitor cocktail for mammalian tissues (Roche Diagnostics, UK). The suspension is then sonicated briefly (10 seconds) using a Vibra-Cell ${ }^{\mathrm{TM}}$ probe sonicator to improve sample handling. Slice lysates are centrifuged at 23,000 g(av) for 20 minutes at $4{ }^{\circ} \mathrm{C}$ and the supernatant collected. The protein content of the slice lysates can be determined using a BCA protein assay (Pierce Endogen, Rockford, USA) and protein concentration normalised prior to immunoblotting or ELISA. Slice lysates are mixed with an equal volume of $2 x$ sample buffer before immunoblotting.

Culture medium can also be collected for analysis of its components, as we recently described for tau and $A \beta^{13}$. Slice culture medium is replaced with Hank's Balanced Salt Solution (HBSS; Life Technologies Ltd). HBSS is collected from the slice cultures and centrifuged at $12,000 \mathrm{~g}$ for $10 \mathrm{~min}$ at $4^{\circ} \mathrm{C}$ to remove cell debris. Protein content in HBSS can be determined by ELISA by standard or sandwich ELISA.

\section{Full protocol for the model development}

\section{Equipment required}

McIllwain Tissue Chopper (RRID:SCR_015798; Mickle Laboratory Engineering Co. Ltd., Surrey, UK)

Stereomicroscope for tissue dissection

Chopping discs (Product code: 752TC-CT; Campden Instruments Ltd., Loughborough, UK)

Blades (Product code: TC752-1; Campden Instruments Ltd., Loughborough, UK)

55mm diameter ashless filter paper (Product code: WHA1442055; Merck, UK)

Flat (cover glass) forceps (Product code: 11074-02; Fine Science Tools, Heidelberg, Germany)

Cohan-Vannas Spring Scissors (Product code: 15000-02; Fine Science Tools, Heidelberg, Germany)

Mayo scissors (Product code: 14010-17; Fine Science Tools, Heidelberg, Germany)

Fine scissors, sharp (Product code: 14060-11; Fine Science Tools, Heidelberg, Germany)

Moria MC17C perforated spoon-mini (Product code: 10370-19; Fine Science Tools, Heidelberg, Germany)

Mini hippocampal dissection tool (Product code: 10099-12; Fine Science Tools, Heidelberg, Germany)

Cell culture treated 6-well plates (Product code: 140675; ThermoFisher Scientific, UK)

Cell culture treated $10 \mathrm{~cm}$ dish (Product code: 172931; ThermoFisher Scientific, UK)

PTFE $30 \mathrm{~mm}$ tissue culture inserts $0.4 \mu \mathrm{m}$ (Product code: PICM03050; Millipore, Fisher Scientific, UK)
Pasteur pipettes - sterile - individually wrapped (Product code: Z350621-400EA; Merck, UK)

30ml Pyrex beaker (Produce code: CLS100030; Merck, UK)

Fine paintbrush

Carbogen (95\% Oxygen / 5\% Carbon Dioxide)

Standard tissue culture incubator $\left(37^{\circ} \mathrm{C} / 5 \%\right.$ Carbon Dioxide)

Buffers and culture medium

Slice Culture Dissection buffer: $1.25 \mathrm{mM} \mathrm{KH}_{2} \mathrm{PO}_{4} \mathrm{pH} 7.4,124 \mathrm{mM}$ $\mathrm{NaCl}, 3 \mathrm{mM} \mathrm{KCl}, 8.19 \mathrm{mM} \mathrm{MgSO}, 2.65 \mathrm{mM} \mathrm{CaCl}_{2}, 3.5 \mathrm{mM}$ $\mathrm{NaHCO}_{3}, 10 \mathrm{mM}$ glucose, $2 \mathrm{mM}$ ascorbic acid, $39.4 \mu \mathrm{M}$ ATP in ultrapure $\mathrm{H}_{2} \mathrm{O}$, sterile filtered $(0.2 \mu \mathrm{m})$.

Slice culture medium: Basal medium eagle (BME), $26.6 \mathrm{mM}$ HEPES, pH 7.1, $19.3 \mathrm{mM} \mathrm{NaCl}, 5 \mathrm{mM} \mathrm{NaHCO}, 511 \mu \mathrm{M}$ ascorbic acid, $40 \mathrm{mM}$ glucose, $2.7 \mathrm{mM} \mathrm{CaCl}, 2.5 \mathrm{mM} \mathrm{MgSO}$, $1 \%$ (v/v) GlutaMAX (Life Technologies, Paisley, UK), $0.033 \%$ $(\mathrm{v} / \mathrm{v})$ insulin, $0.5 \%(\mathrm{v} / \mathrm{v})$ penicillin/streptomycin (Life Technologies), in ultrapure $\mathrm{H}_{2} \mathrm{O}$, sterile filtered $(0.2 \mu \mathrm{m})$, plus $25 \%$ $(\mathrm{v} / \mathrm{v})$ heat inactivated horse serum (ThermoFisher, UK).

\section{Methods}

\section{Brain extraction:}

Experiments are performed under sterile conditions with tools sterilised by autoclaving prior to use. $70 \% \mathrm{EtOH}$ is used to sterilize equipment and surfaces throughout the experiment. Postnatal day 8 or $9 \mathrm{WT}$ or $3 \mathrm{xTg}-\mathrm{AD}$ mice are used (Figure 1A-C).

1. Pups are decapitated using Mayo scissors and death confirmed.

2. Heads are transferred to a $10 \mathrm{~cm}$ tissue culture dish containing oxygenated ice-cold dissection buffer.

3. Fine scissors are used to remove hair and skin, cutting anteriorly from the base of the skull along the midline, revealing the brain and skull.

4. Small spring scissors are used to carefully cut through the midline of the skull.

5. The brain is bisected through the midline while remaining in the skull using a razor blade.

6. The hippocampal dissection tool is used to cleanly remove the remove brainstem, cerebellum and thalamus which are discarded. The cortex, hippocampus and associated regions remain intact.

7. The remaining tissue is removed from the skull and transferred to a glass beaker containing oxygenated dissection buffer.

8. Repeat for the other hemi-brain. One hemi-brain will remain in dissection buffer, regularly re-oxygenated, while the other is processed. 
A

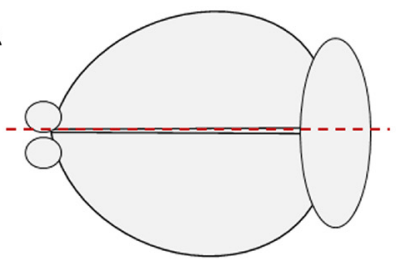

B

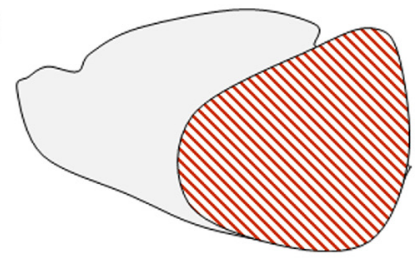

C

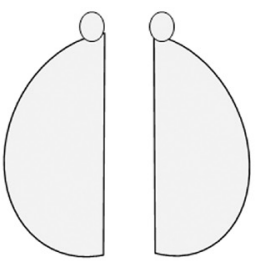

D
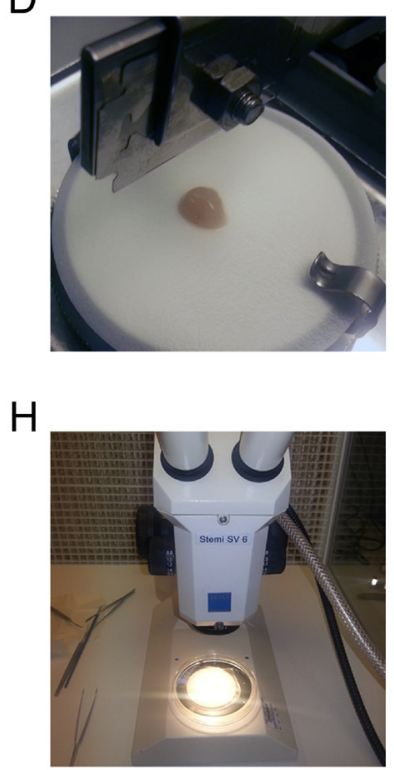

E

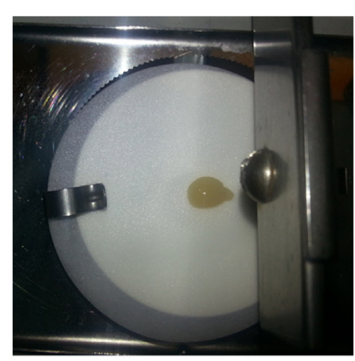

I

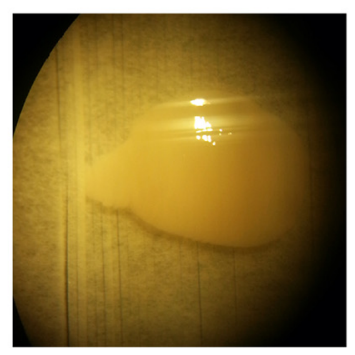

F

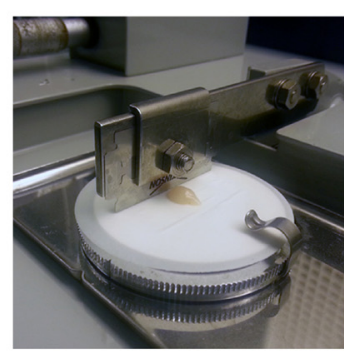

J

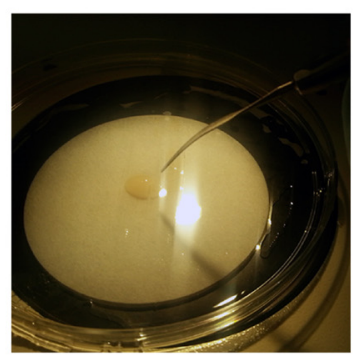

G

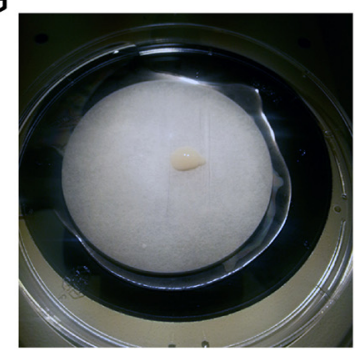

K

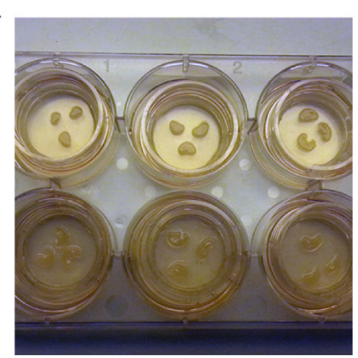

Figure 1. Preparation of organotypic brain slice cultures. (A) After removal from the skull, brains are bisected along the midline using a razor blade. (B) The thalamus, cerebellum and brain stem are removed using the hippocampal dissection tool leaving the cortex, hippocampus and connected brain regions. (C) Two hemi-brains are kept in oxygenated dissection buffer throughout the procedure; one hemi-brain is stored whilst the other is processed. (D) A hemi-brain is placed on dampened filter paper on the cutting surface of a Mcllwain tissue chopper. (E-F) $350 \mu \mathrm{m}$ coronal slices are cut. (G-J) Slice cultures are sequentially separated under a dissection microscope using a hippocampal dissection tool. (K) Three slices are plated per well on Millipore membrane inserts in 6 well plates. Three consecutive slices can be placed in each well or slices plated randomly depending on experimental needs. Cultures are maintained by replacing the culture medium every 2-3 days.

\section{Slice culture preparation (Figure 1D-K):}

9. $1 \mathrm{~mL}$ of slice culture medium is added to each well of a 6-well culture plate. Flat cover glass forceps are used to add a Millicell culture insert into each well. The plate is returned to a $37^{\circ} \mathrm{C}$ incubator to ensure that culture medium is pre-warmed before slices are plated.

10. A plastic chopping disc and fresh filter paper is placed on the cutting stage of a McIlwain tissue chopper. Three to four drops of dissection solution are used to dampen the filter paper and allow the hemi-brain to remain in place.

11. A hemi brain is placed onto the filter paper and oriented for coronal sectioning (the front of the brain on the right-hand side).

12. A drop of dissection solution is added to the brain to prevent the cutting blade from sticking.
13. The section size on the McIllwain tissue chopper is adjusted to $350 \mu \mathrm{m}$. The blade should be manually positioned adjacent to the frontal region of the brain.

14. The tissue chopper is started - the automated razor blade will cut $350 \mu \mathrm{m}$ sections until manually switched off. The speed of cutting can be adjusted if necessary.

15. The hemi-brain, remaining on the filter paper, is transferred to a fresh $10 \mathrm{~cm}$ dish containing oxygenated dissection solution, and the dish is placed under a dissection microscope.

16. Slices are manually separated using the hippocampal dissection tool, taking care to avoid ripping tissue. Using a plastic Pasteur pipette, individual slices are transferred to culture inserts in 6-well plate.

17. From the leading edge (frontal cortex), three consecutive slices are positioned in each culture insert. Each hemi-brain 
is sectioned into 18 slices, equivalent to one 6-well plate. Alternatively, slices can be plated randomly and distributed throughout wells allowing the study of frontal, middle and rostral sections within each well.

18. Care should be taken to ensure that slices do not overlap or make contact with the sides of the insert. A fine paintbrush can be used to move the slices and to ensure that no areas of the slices are folded or wrinkled.

19. Excess dissection solution is removed from the slice culture inserts, and the 6-well plate is returned to an incubator and maintained in humid conditions at $37^{\circ} \mathrm{C}$ with $5 \% \mathrm{CO}_{2}$.

\section{Slice culture maintenance:}

20. In sterile conditions, approximately three hours after plating a glass Pasteur pipette is used to aspirate culture medium. $1 \mathrm{~mL}$ pre-warmed fresh sterile culture medium is then added.

21. Brain slices are incubated in humid conditions at $37^{\circ} \mathrm{C}$ with $5 \% \mathrm{CO}_{2}$. Culture medium is replaced every 2 to 3 days, taking care not to move the inserts within each well. Any excess medium which collects in the insert is also removed during media changes, taking care not to disturb the slices.

22. Slice cultures can be analysed from 14 days after plating, at which time lactate dehydrogenase release should have returned to basal levels ${ }^{10}$.

\section{NOTES: Practical considerations and tips}

- P8-P9 pups are used in this method, however other ages of pups are described in publications from other groups. It is likely that some optimisation may be required depending on the strain or transgenic line of mice being used.

- Slice cultures are initially white in colour, but become translucent after 7 to 10 days in culture. White tissue remaining at this point is likely to signify unhealthy or dead tissue.

- It is important to cleanly remove all of the thalamus, cerebellum and brainstem during dissection since these are detrimental to slice survival under these conditions. These tissues can be cultured but using alternative protocols.

- It is important that excess dissection buffer is removed from the slice cultures once they have been plated since prolonged exposure to this buffer in culture can affect slice health.

\section{Results}

\section{Characterisation of the model: Organotypic brain slice} cultures from 3xTg-AD mice recapitulate molecular features of $A D$ and show an accelerated disease phenotype compared to in vivo

We have previously characterised organotypic brain slice cultures prepared from $3 \times \mathrm{Tg}-\mathrm{AD}$ mice in comparison to brain from aged in vivo $3 \mathrm{xTg}-\mathrm{AD}$ mice $^{13}$. We examined abnormalities in $\beta$-amyloid and tau that accumulate in $\mathrm{AD}$ brain. We found that
3xTg-AD slice cultures show an accelerated development of highly phosphorylated and oligomeric/64kDa tau species, some of which redistributed to synaptic compartments by 28 days in vitro $(D I V)$. Similar changes in vivo are typically observed from 12 months of age. An accelerated accumulation of potentially pathogenic $A \beta$ species were also observed in brain slice cultures from $3 \times \mathrm{Tg}$-AD mice, with significantly increased A $\beta 1-42$ levels detected at $28 \mathrm{DIV}$ in slices. In comparison, we could only detect significant changes in $A \beta 1-42$ amounts in 3xTg-AD brain in 12-month old mice. Thus, disease-associated protein species show an accelerated accumulation in long-term brain slice cultures in comparison to in vivo. Using differential centrifugation approaches we were also able to show the differential accumulation of phosphorylated and dephosphorylated tau species in synaptic compartments and at membranes, in agreement with previous reports using human tissue and primary cell cultures ${ }^{18,19}$. Table 1 provides a summary of molecular changes in the slice culture model in comparison to findings made using tissue from aged $3 \mathrm{xTg}-\mathrm{AD}$ mice. Primary data is available here (Dataset $1^{20}$ ).

There is also a great deal of versatility in the methods that can be used to assess disease changes in this model. We have confirmed that methods including, but not limited to the following, can be used with slice cultures; biochemical changes can be assessed by ELISA or immunoblotting, slice cultures can be examined by immunohistochemistry and confocal microscopy, sufficient material is present to allow differential centrifugation to enrich cell compartments such as synaptosomes, membrane and cytosol. Additionally, cell death can be measured using lactate dehydrogenase assays and the release of disease-associated proteins into culture medium can be quantified ${ }^{13,21}$. Others have also shown that brain slice cultures are amenable to ultrastructural analysis ${ }^{22}$, and live calcium imaging ${ }^{11}$.

Validation of the model: Organotypic brain slice cultures can be used to assess acute pharmacological treatments and to determine drug targets

In addition to comparing molecular features of $\mathrm{AD}$ in slice cultures in comparison to in vivo, we also validated the use of slice cultures for studying the effects on tau phosphorylation of acute application of compounds in comparison to their reported effects in previously published in vivo studies.

Lithium chloride $(\mathrm{LiCl})$ can inhibit activity of the prominent tau kinase, glycogen synthase kinase- $3 \beta(\mathrm{GSK}-3)^{23}$, which targets many of the tau residues known to be aberrantly phosphorylated in $\mathrm{AD}^{16}$. Treatment of 12-month-old 3xTg-AD mice for 3 months with the GSK-3 inhibitor, $\mathrm{LiCl}$, was shown to reduce phosphorylation of tau at Thr 181, Ser 202/Thr 205, Thr 231, and Thr 212/Ser 214, but not Ser 396/40424. We found that application of $\mathrm{LiCl}$ for $4 \mathrm{~h}$ to $3 \mathrm{xTg}-\mathrm{AD}$ brain slice cultures at 28 days days in vitro (DIV) resulted in significantly reduced tau phosphorylation at the Ser396/404 and Ser202/Thr205 epitopes, in addition to causing a subtle reduction in total tau amounts when compared to slices treated with control $(\mathrm{NaCl})$. There was also a notable shift in the apparent molecular weight of tau in lysates from $\mathrm{LiCl}$ treated slice cultures, which is characteristic of reduced tau phosphorylation ${ }^{15}$. 
Table 1. Biochemical and pathological features of 3xTg-AD organotypic brain slices in comparison to in vivo $3 \times \mathrm{Tg}$-AD brain and AD brain. Primary references are shown. AD: Alzheimer's disease; DIV: days in vitro.

\begin{tabular}{|c|c|c|c|}
\hline Feature & AD brain & 3xTg-AD mice in vivo & $3 x T g-A D$ ex vivo brain slice \\
\hline Tau phosphorylation & Increased at many sites ${ }^{16}$ & $\begin{array}{l}\text { Increased in 12-15-month old mice }{ }^{12} \\
\text { in hippocampus but not cortex }\end{array}$ & $\begin{array}{l}\text { Increased at Ser202 and } \\
\text { Ser396/404 by } 28 \text { DIV }^{15}\end{array}$ \\
\hline $\begin{array}{l}\text { High molecular weight } \\
\text { (HMW) tau/tau aggregation }\end{array}$ & $\begin{array}{l}\text { Tau aggregates in characteristic } \\
\text { neurofibrillary pathology }{ }^{17}\end{array}$ & $\begin{array}{l}\text { HMW and sarkosyl-insoluble } \\
\text { tau aggregates by } 12 \text { months of } \\
\text { age }{ }^{13} \text {, tau aggregates and NFTs } \\
\text { at } 18 \text { months of age }{ }^{12} \text {. }\end{array}$ & $64 \mathrm{kDa}$ tau at 21 and 28 DIV $^{13}$ \\
\hline $\mathbf{A \beta}$ & $\begin{array}{l}\text { Increased } A \beta \text { deposition in } \\
\text { hallmark plaques } \\
\text { ha,26 }\end{array}$ & $\begin{array}{l}\text { Increased } A \beta-42 \text { at } \\
6-12 \text { months of age }{ }^{12,13,31} \text {, plaques } \\
\text { from } 6 \text { months of age }{ }^{12}\end{array}$ & Increased $A \beta-42$ by 14 DIV $^{13}$ \\
\hline Synaptic protein loss & $\begin{array}{l}\text { Loss of PSD-95 and } \\
\text { synapto-physin }{ }^{27,28}\end{array}$ & $\begin{array}{l}\text { Loss of PSD-95 and synaptophysin } \\
\text { at } 13 \text { months of age }{ }^{32} \text {, but not } \\
12 \text { months of age }\end{array}$ & $\begin{array}{l}\text { No loss of PSD-95 or } \\
\text { synaptophysin }{ }^{13}\end{array}$ \\
\hline Synaptic tau & $\begin{array}{l}\text { Tau in AD and control synapses, } \\
\text { but phosphorylated tau } \\
\text { species only in AD synapses }{ }^{29}\end{array}$ & $\begin{array}{l}\text { Tau at synapses transiently } \\
\text { increased at } 1-2 \text { month of age, } \\
\text { then returning to control levels } \\
\text { until } 12 \text { months of age }{ }^{13}\end{array}$ & $\begin{array}{l}\text { Tau at synapses transiently } \\
\text { increased at } 14 \text { DIV, then } \\
\text { returning to normal levels until } \\
28 \text { DIV }^{13}\end{array}$ \\
\hline Synaptic APP & $\begin{array}{l}\text { APP not increased in AD } \\
\text { synapses }^{30}\end{array}$ & $\begin{array}{l}\text { Increased APP in synapses at } \\
1-2 \text { months of age, but not at } \\
\text { later ages up to } 12 \text { months }^{13}\end{array}$ & No change in synaptic APP ${ }^{13}$ \\
\hline
\end{tabular}

Another potential therapeutic approach for AD is to use microtubule-stabilising agents to recover the loss of function, which occurs following the detachment of phosphorylated tau from the microtubule cytoskeleton ${ }^{23}$. Neuroprotective effects of the peptide NAPVSIPQ have previously been reported in 12-month-old 3xTg-AD mice. Mice administered NAPVSIPQ for 3 months showed reduced phosphorylation of tau at Ser 202/Thr 205 and Thr 231, but not at Ser 202 alone. Treatment of 28 DIV 3xTg-AD slice cultures with $100 \mathrm{nM}$ NAPVSIPQ for $24 \mathrm{~h}$ significantly reduced tau phosphorylation at the Thr231 epitope, but did not alter the total amount of tau when compared to control cultures ${ }^{15}$, thus we find that equivalent treatment of $3 \times \mathrm{Tg}-\mathrm{AD}$ organotypic brain slice cultures recapitulates previous in vivo findings conducted in $3 \mathrm{xTg}-\mathrm{AD}$ mice ${ }^{24,33,34}$.

Primary data is available at https://www.ncbi.nlm.nih.gov/pme/ articles/PMC5547074/ ${ }^{15}$.

We also used the slice culture model to identify novel taudirected effects of BTA-EG ${ }_{4}^{15}$, a compound that had previously shown $\mathrm{A} \beta$-binding effects and synaptic protection ${ }^{35-37}$. A growing body of publications have further demonstrated the tractability of the slice culture system, including pharmacological manipulation of $\mathrm{A} \beta$ production $^{9}$ and tau aggregation ${ }^{11}$, in addition to modulation of microglial composition to examine the phagocytic action of microglia on $\mathrm{A} \beta$ deposits ${ }^{22}$.

These data suggest that potential therapeutic agents can be sensitively examined in organotypic brain slice culture models. Since a number of methods can be applied to study slice culture tissues, this system should be considered as a replacement for in vivo studies with molecular and cellular study parameters and when end-points do not include life-span or behavioural assessment. Certainly, in academic and industrial laboratories, slice cultures should provide an excellent system for medium throughput drug screening or range-finding studies.

Dataset 1. Primary data for molecular changes in the slice culture model in comparison to findings made using tissue from aged 3xTg-AD mice

http://dx.doi.org/10.5256/f1000research.14500.d200832

\section{Discussion}

Organotypic brain slice cultures can reduce the number of animals required for some in vivo studies

Depending on the nature of the experiment, one postnatal day 8 or 9 pup can provide an $\mathrm{n}=36$ for immunohistochemical analysis, and a single well containing three slices can be combined to give $n=12$ for biochemical analysis or compound screening. For example, the preparation of slice cultures from only six postnatal pups would allow the opportunity to study 12 time-points in six different animals, a reduction in numbers of $91 \%$ in comparison to the 72 mice that would be required for an in vivo aging study. In addition, since multiple time points will be assessed in tissues from the same animals, experimental within-group variation is substantially reduced.

Take-up of this method within academic laboratories in the UK appears to be growing, however it is very difficult to accurately quantify the number of animals that have not been used as a result of researchers preparing slice cultures in preference to in vivo experimentation. Within our own laboratories, we estimate that our in vivo experimentation has reduced by 
approximately $20 \%$ as we train more researchers in the method of brain slice culture preparation.

\section{An adaptable model for neurodegeneration research}

While we have focussed on AD research in this article, organotypic brain slice cultures are equally suitable for research into a range of other neurodegenerative and neurological conditions, as well as for basic neuroscientific research (reviewed by 8 ). Slice cultures can also be prepared specifically from the hippocampus ${ }^{9}$ or from other tissues such as spinal $\operatorname{cord}^{38}$; the latter being used to investigate prion-like properties of mutant SOD1 proteins in amyotrophic lateral sclerosis. The technique is not limited to mice, rats are commonly used ${ }^{8}$ and methods are emerging to allow long-term culture of human organotypic brain slice cultures ${ }^{39}$. There are no major restrictions on uptake of this model since it requires only modest investment in terms of equipment provision. Training in tissue dissection and slicing may be beneficial, but the technique can readily be learned with practice.

\section{Conclusions}

Here, we describe a detailed method for the preparation of long-term organotypic brain slice cultures from postnatal mice. We describe our work previously showing that slice cultures prepared from 3xTg-AD mice recapitulate important molecular and cellular features of in vivo disease development and the human disease phenotype. We also summarise the versatility of the model for drug discovery and the acute screening of compounds. Slice cultures show a significant acceleration in the timescale in which disease features develop, with relevant pathological changes observed at 28 days in vitro as opposed to 12 months in vivo in $3 \mathrm{x}-\mathrm{TgAD}$ mice. We suggest that organotypic brain slice cultures can be used to replace several in vivo studies and that their widespread uptake could reduce the number of animals used in neurodegenerative disease research by 20-50\%. This could be achieved if slice cultures were used in place of purely biochemical and immunohistological studies, and for experiments not reliant on behavioural outcomes.

\section{Data availability}

Dataset 1: Primary data for molecular changes in the slice culture model in comparison to findings made using tissue from aged 3xTg-AD mice. DOI: 10.5256/f1000research.14500. d200832 20

\section{Competing interests}

No competing interests were disclosed.

\section{Grant information}

This work was supported by funding from the National Centre for Replacement, Refinement and Reduction of Animals in Research (NC/K500343/1 to WN) and the Biotechnology and Biological Sciences Research Committee (BB/L502601/1 to WN).

\section{Supplementary material}

Supplementary File 1: ARRIVE checklist.

Click here to access the data.

1. Ellenbroek B, Youn $\mathrm{J}$ : Rodent models in neuroscience research: is it a rat race? Dis Model Mech. 2016; 9(10): 1079-1087. PubMed Abstract | Publisher Full Text | Free Full Text

2. Arber C, Lovejoy C, Wray S: Stem cell models of Alzheimer's disease: progress and challenges. Alzheimers Res Ther. 2017; 9(1): 42. PubMed Abstract | Publisher Full Text | Free Full Text

3. Gähwiler BH, Capogna M, Debanne D, et al:: Organotypic slice cultures: a technique has come of age. Trends Neurosci. 1997; 20(10): 471-477. PubMed Abstract | Publisher Full Text

4. Hailer NP, Jarhult JD, Nitsch R: Resting microglial cells in vitro: analysis of morphology and adhesion molecule expression in organotypic hippocampal slice cultures. Glia. 1996; 18(4): 319-331. PubMed Abstract | Publisher Full Text

5. Stoppini L, Buchs PA, Muller D: A simple method for organotypic cultures of nervous tissue. J Neurosci Methods. 1991; 37(2): 173-182. PubMed Abstract | Publisher Full Text

6. De Simoni A, Griesinger CB, Edwards FA: Development of rat CA1 neurones in acute versus organotypic slices: role of experience in synaptic morphology and activity. J Physiol. 2003; 550(Pt 1): 135-147. PubMed Abstract | Publisher Full Text | Free Full Text

7. De Simoni A, Yu LM: Preparation of organotypic hippocampal slice cultures: interface method. Nat Protoc. 2006; 1(3): 1439-1445. PubMed Abstract | Publisher Full Text

8. Humpel C: Organotypic vibrosections from whole brain adult Alzheimer mice (overexpressing amyloid-precursor-protein with the Swedish-Dutch-lowa mutations) as a model to study clearance of beta-amyloid plaques. Front Aging Neurosci. 2015; 7: 47.

PubMed Abstract | Publisher Full Text | Free Full Text

9. Harwell CS, Coleman MP: Synaptophysin depletion and intraneuronal $\mathbf{A} \beta$ in organotypic hippocampal slice cultures from huAPP transgenic mice. Mol Neurodegener. 2016; 11(1): 44 PubMed Abstract | Publisher Full Text | Free Full Text

10. Duff K, Noble W, Gaynor K, et al:: Organotypic slice cultures from transgenic mice as disease model systems. $J$ Mol Neurosci. 2002; 19(3): 317-320. PubMed Abstract | Publisher Full Text

11. Messing L, Decker JM, Joseph M, et al.: Cascade of tau toxicity in inducible 
hippocampal brain slices and prevention by aggregation inhibitors. Neurobiol Aging. 2013; 34(5): 1343-1354

PubMed Abstract | Publisher Full Text | Free Full Text

12. Oddo S, Caccamo A, Shepherd JD, et al:: Triple-transgenic model of Alzheimer's disease with plaques and tangles: intracellular Abeta and synaptic dysfunction. Neuron. 2003; 39(3): 409-421.

PubMed Abstract | Publisher Full Text

13. Croft CL, Wade MA, Kurbatskaya $\mathrm{K}$, et al:: Membrane association and release of wild-type and pathological tau from organotypic brain slice cultures. Cell Death Dis. 2017; 8(3): e2671.

PubMed Abstract | Publisher Full Text | Free Full Text

14. Sundstrom L, Morrison B 3rd, Bradley M, et al.: Organotypic cultures as tools fo functional screening in the CNS. Drug Discov Today. 2005; 10(14): 993-1000. PubMed Abstract | Publisher Full Text

15. Croft CL, Kurbatskaya K, Hanger DP, et al.: Inhibition of glycogen synthase kinase-3 by BTA-EG, reduces tau abnormalities in an organotypic brain slice culture model of Alzheimer's disease. Sci Rep. 2017; 7(1): 7434 PubMed Abstract | Publisher Full Text | Free Full Text

16. Guo T, Noble W, Hanger DP: Roles of tau protein in health and disease. Acta Neuropathol. 2017; 133(5): 665-704.

PubMed Abstract | Publisher Full Text | Free Full Text

17. Grundke-lqbal I, Iqbal K, Quinlan M, et al:: Microtubule-associated protein tau. A component of Alzheimer paired helical filaments. J Biol Chem. 1986; 261(13): 6084-6089.

PubMed Abstract

18. Perez-Nievas BG, Stein TD, Tai HC, et al:: Dissecting phenotypic traits linked to human resilience to Alzheimer's pathology. Brain. 2013; 136(Pt 8): 2510-2526. PubMed Abstract | Publisher Full Text | Free Full Text

19. Pooler AM, Usardi A, Evans CJ, et al.: Dynamic association of tau with neurona membranes is regulated by phosphorylation. Neurobiol Aging. 2012; 33(2): 431.e427-438.

PubMed Abstract | Publisher Full Text

20. Croft CL, Noble W: Dataset 1 in: Preparation of organotypic brain slice culture for the study of Alzheimer's disease. F1000Research. 2018 Data Source

21. Fontaine SN, Zheng D, Sabbagh JJ, et al:: DnaJ/Hsc70 chaperone complexes control the extracellular release of neurodegenerative-associated proteins. EMBO J. 2016; 35(14): 1537-1549.

PubMed Abstract | Publisher Full Text | Free Full Text

22. Hellwig $S$, Masuch $A$, Nestel $S$, et al.: Forebrain microglia from wild-type but not adult 5XFAD mice prevent amyloid- $\beta$ plaque formation in organotypic hippocampal slice cultures. Sci Rep. 2015; 5: 14624 PubMed Abstract | Publisher Full Text | Free Full Text

23. Noble W, Pooler AM, Hanger DP: Advances in tau-based drug discovery. Expert Opin Drug Discov. 2011; 6(8): 797-810. PubMed Abstract | Publisher Full Text | Free Full Text

24. Caccamo $A$, Oddo $S$, Tran $L X$ et al: Lithium reduces tau phosphorylation but not $\mathrm{A}$ beta or working memory deficits in a transgenic model with both plaques and tangles. Am J Pathol. 2007; 170(5): 1669-1675. PubMed Abstract | Publisher Full Text | Free Full Text

25. Glenner GG, Wong CW: Alzheimer's disease and Down's syndrome: sharing of a unique cerebrovascular amyloid fibril protein. Biochem Biophys Res Commun. 1984; 122(3): 1131-1135.

PubMed Abstract | Publisher Full Text

26. O'Brien RJ, Wong PC: Amyloid precursor protein processing and Alzheimer's disease. Annu Rev Neurosci. 2011; 34: 185-204.

PubMed Abstract | Publisher Full Text | Free Full Text

27. Masliah E, Mallory M, Alford M, et al:: Altered expression of synaptic proteins occurs early during progression of Alzheimer's disease. Neurology. 2001; 56(1): 127-129. PubMed Abstract | Publisher Full Text

28. Kurbatskaya K, Phillips EC, Croft CL, et al.: Upregulation of calpain activity precedes tau phosphorylation and loss of synaptic proteins in Alzheimer's disease brain. Acta Neuropathol Commun. 2016; 4: 34 . PubMed Abstract | Publisher Full Text | Free Full Text

29. Tai HC, Serrano-Pozo A, Hashimoto T, et al:: The synaptic accumulation of hyperphosphorylated tau oligomers in Alzheimer disease is associated with dysfunction of the ubiquitin-proteasome system. Am J Pathol. 2012; 181(4): 1426-1435.

PubMed Abstract | Publisher Full Text | Free Full Text

30. Gylys KH, Fein JA, Yang F, et al:: Synaptic changes in Alzheimer's disease: increased amyloid-beta and gliosis in surviving terminals is accompanied by decreased PSD-95 fluorescence. Am J Pathol. 2004; 165(5): 1809-1817. PubMed Abstract | Publisher Full Text | Free Full Text

31. Oddo S, Caccamo A, Kitazawa M, et al:: Amyloid deposition precedes tangle formation in a triple transgenic model of Alzheimer's disease. Neurobiol Aging. 2003: 24(8): 1063-1070.

PubMed Abstract | Publisher Full Text

32. Revilla S, Ursulet S, Álvarez-López MJ, et al.: Lenti-GDNF gene therapy protects against Alzheimer's disease-like neuropathology in 3xTg-AD mice and MC65 cells. CNS Neurosci Ther. 2014; 20(11): 961-972. PubMed Abstract | Publisher Full Text

33. Matsuoka Y, Gray AJ, Hirata-Fukae C, et al.: Intranasal NAP administration reduces accumulation of amyloid peptide and tau hyperphosphorylation in a transgenic mouse model of Alzheimer's disease at early pathological stage. J Mol Neurosci. 2007; 31(2): 165-170.

PubMed Abstract | Publisher Full Text

34. Matsuoka $\mathrm{Y}$, Jouroukhin $\mathrm{Y}, \mathrm{Gray}$ AJ, et al:: A neuronal microtubule-interacting agent, NAPVSIPQ, reduces tau pathology and enhances cognitive function in a mouse model of Alzheimer's disease. J Pharmacol Exp Ther. 2008; 325(1): $146-153$.

PubMed Abstract | Publisher Full Text

35. Inbar P, Li CQ, Takayama SA, et al:: Oligo(ethylene glycol) derivatives of thioflavin T as inhibitors of protein-amyloid interactions. Chembiochem. 2006; $7(10)$ : 1563-1566 PubMed Abstract | Publisher Full Text

36. Megill A, Lee T, DiBattista AM, et al.: A tetra(ethylene glycol) derivative of benzothiazole aniline enhances Ras-mediated spinogenesis. J Neurosci. 2013; 33(22): 9306-9318

PubMed Abstract | Publisher Full Text | Free Full Text

37. Habib LK, Lee MT, Yang J: Inhibitors of catalase-amyloid interactions protect cells from beta-amyloid-induced oxidative stress and toxicity. $\mathrm{J} \mathrm{Biol} \mathrm{Chem.}$ 2010; 285(50): 38933-38943.

PubMed Abstract | Publisher Full Text | Free Full Text

38. Ayers Jl, Diamond J, Sari A, et al:: Distinct conformers of transmissible misfolded SOD1 distinguish human SOD1-FALS from other forms of familial and sporadic ALS. Acta Neuropathol. 2016; 132(6): 827-840. PubMed Abstract | Publisher Full Text | Free Full Text

39. Schwarz N, Hedrich UBS, Schwarz H, et al:: Human Cerebrospinal fluid promotes long-term neuronal viability and network function in human neocortical organotypic brain slice cultures. Sci Rep. 2017; 7(1): 12249. PubMed Abstract | Publisher Full Text | Free Full Text 


\section{Open Peer Review}

\section{Current Peer Review Status:}

\section{Version 1}

Reviewer Report 29 May 2018

https://doi.org/10.5256/f1000research.15785.r34402

(C) 2018 Barnett S. This is an open access peer review report distributed under the terms of the Creative Commons Attribution License, which permits unrestricted use, distribution, and reproduction in any medium, provided the original work is properly cited.

\section{Susan C. Barnett}

Institute of Infection, Immunity and Inflammation, College of Medical, Veterinary and Life Sciences, University of Glasgow, Glasgow, UK

This is a well written clearly explained method for making slice cultures from 3xTg-AD mice for the study of Alzheimer's disease. It is useful to have a step by step account with hints to describe this method as in general slice cultures can be difficult to reproduce and be consistent. There is a good description of how this method fulfils NC3Rs criteria.

Minor points:

1. It would be very helpful to have a little more justification of why this is a novel method when many publications can be seen using slice cultures for Alzheimers research, even from transgenic mice.

2. It was a little bit confusing on the section stating: In brief, slice cultures are cut whilst still on their membranes and then treated as free-floating sections. Is this illustrated in Figure 1? If so could be made clearer?

3. Not convinced the $n=12$ from one pup statement is correct, as this would be replicates. $N$ usually refers to different biological repeats.

4. It would be really useful to see example of the slices when validated, with examples of staining. Can microglia be seen and how good is the anatomy of the slices.

5. The LDH was not explained enough and perhaps the time course could have been shown.

Are a suitable application and appropriate end-users identified?

Yes

If applicable, is the statistical analysis and its interpretation appropriate?

Yes 
Are the 3Rs implications of the work described accurately?

Yes

Is the rationale for developing the new method (or application) clearly explained?

Partly

Is the description of the method technically sound?

Yes

Are sufficient details provided to allow replication of the method development and its use by others?

Yes

If any results are presented, are all the source data underlying the results available to ensure full reproducibility?

Yes

Are the conclusions about the method and its performance adequately supported by the findings presented in the article?

Yes

Competing Interests: No competing interests were disclosed.

Reviewer Expertise: Referee suggested by the NC3Rs for their scientific expertise and experience in assessing 3Rs impact. Additional expertise: glia cell biologist, CNS co-cultures to study myelination, spinal cord injury

I confirm that I have read this submission and believe that I have an appropriate level of expertise to confirm that it is of an acceptable scientific standard.

Reviewer Report 22 May 2018

https://doi.org/10.5256/f1000research.15785.r34019

(C) 2018 Humpel C. This is an open access peer review report distributed under the terms of the Creative Commons Attribution License, which permits unrestricted use, distribution, and reproduction in any medium, provided the original work is properly cited.

\section{Christian Humpel}

Laboratory of Psychiatry and Experimental Alzheimer's Research, Medical University of Innsbruck, Innsbruck, Austria

This is a well done contribution by a group having good experience in organotypic brain slice cultures. The MS is well written, the methods clear and the pictures of good quality. I have a few suggestions: 
1. Please provide more details in the Abstract, especially, on the organotypic brain slice model (3xTg mice, chopper slices, $350 \mu \mathrm{m}$, postnatal d8-9, cultured for $>2$ weeks on $0.4 \mu \mathrm{m}$ pore semipermeable membranes). Please also add this information in the Box research highlights. This is important to see on one view which kind of slices you mean.

2. I suggest that you are more careful about the used number of animals. In Abstract you write an estimated 20,000 mice per year for dementia research and on page 3, right col. sec. paragr. you write ... were used in AD research, and you write 20,000 transgenic; assuming from 30 mice per paper. What do you mean: (1) per year in UK, Europe or the world?, (2) total mice per year or only transgenic per year? (3) based on which fact you assume 30 mice per paper (value 30 is just your thoughts or is this based on an official reference?). I suggest that you check an EU report on the total number of animals/mice/transgenic, or you check your national institution (and also give the official reference). Such rough values could be very problematic.

3. Page 3 third paragr: .... importantly, slice cultures are prepared from neonatal mice ... this (neonatal) should be explained as it is unclear.

4. It would be helpful to give the average weight of the postnatal d8-9 mice. We usually weigh them, to be sure about the stage. Or do you have other rules to be sure on the correct stage. Also mention up to which age does your model work?

5. Page 5, point 6: typo: $2 x$ remove

6. Page 7 right col, last paragr: .....when reporting on the phosphorylation of tau via $\mathrm{LiCl}$ and GSK-3, the authors may cite the recent paper Foidl and Humpel (2018) in Frontiers Aging Neurosci. on hyperphosphorylation of tau in organotypic brain slices induced by okadaic acid. In this respect also the review on brain culture slices by Humpel (2015) in Neuroscience should be cited (page 4, left col, line, 14).

7. Please explain better your definition of the n-number (page 8 , right col.) .... one postnatal d8 or 9 pup can provide an $n=36$. I think that one mouse only gives an $n=1$; for an experiment you need at least 6-8 different mice ( $n=6-8)$; but one mouse can give up to 36 different treatments (or in duplicate $2 \times 18$ ). What is your suggestion on power calculations (how many slices per group?). Please explain better any statistical issues.

8. Finally, please state in your conclusion the limits of the brain slices; how to study genetic (familiar) versus sporadic $A D$, how comparable is the developmental stage with the adult stage (maturation of neurons after 2 weeks in culture?), how long do you need to culture to get at least an early comparable adult stage, what about axonal networks and the problem of axotomy.

\section{Are a suitable application and appropriate end-users identified? Yes}

If applicable, is the statistical analysis and its interpretation appropriate? Not applicable 
Are the 3Rs implications of the work described accurately?

Yes

Is the rationale for developing the new method (or application) clearly explained?

Yes

Is the description of the method technically sound?

Yes

Are sufficient details provided to allow replication of the method development and its use by others?

Yes

If any results are presented, are all the source data underlying the results available to ensure full reproducibility?

Yes

Are the conclusions about the method and its performance adequately supported by the findings presented in the article?

Yes

Competing Interests: No competing interests were disclosed.

Reviewer Expertise: Alzheimer, brain slices, transgenic, diagnosis, platelets, monocytes, plaques, tau

I confirm that I have read this submission and believe that I have an appropriate level of expertise to confirm that it is of an acceptable scientific standard.

Reviewer Report 18 May 2018

https://doi.org/10.5256/f1000research.15785.r34021

(C) 2018 Durrant C. This is an open access peer review report distributed under the terms of the Creative Commons Attribution License, which permits unrestricted use, distribution, and reproduction in any medium, provided the original work is properly cited.

\section{Claire S. Durrant}

John van Geest Centre for Brain Repair, Department of Clinical Neurosciences, University of Cambridge, Cambridge, UK

This well written method article describes the process of making whole brain organotypic slices from 3xTg-AD mice to use for studies of Alzheimer's related pathology. The main focus of the paper is on how this method can be used to reduce and refine the use of animals in Alzheimer's disease $(A D)$ research. The methods of creating and maintaining the slice cultures are clearly described in detail allowing for future replication by other groups. Specific protocols for preparing 
slice material for immunostaining, immunoblotting and ELISA are also described effectively. The experimental results given from previously published work, as well as the cited work of others, serve as excellent examples of how this system can be utilised in AD studies with particular emphasis on the 3Rs. In particular, the authors highlight the ability to test multiple timepoints or multiple compounds on tissue from the same animal resulting in not only a reduction in the number of animals required, but also better controls for biological variability. I agree with the authors' conclusions that brain slice models of Alzheimer's disease can partly replace biochemical/cellular/molecular studies in older animals that have developed pathology.

The authors provide a useful comparison between changes observed in human brain, aged 3xTgAD brain and brain slice cultures, with the raw data provided. Their observations that slice cultures show an accelerated phenotype when compared to adult mice is interesting and in agreement with what we have seen in hippocampal slices cultures from TgCRND8 mice (reference 9 in this paper). Future work seeking to elucidate why this is the case could be very informative.

Whilst the methods in this paper have been previously described elsewhere, the detailed description of culture preparation, experimental design and methods for analysis in the context of $A D$ are a useful and timely addition to the literature. The tips relating to assessment of culture health (a white slice becoming translucent) and issues to look out for that may harm the health of the slices (excess medium on the membrane insert) are completely aligned with our own experience and very useful for someone seeking to perform slice culture experiments for the first time. I have no reservations in approving this manuscript.

\section{Minor comments:}

Whilst actin is a valid control protein in western blots, it could be argued that beta-III tubulin (or alternative neuronal markers) may be a more informative control when normalising synaptic protein levels. This controls for any difference in neuronal number between samples which may alter synaptic protein levels in the absence of a synaptic specific change. This would be more important in cases where synaptic protein levels are down, but there is also evidence for neuronal loss.

It would be interesting to see whether the 3xTg-AD brain slices lose synaptic proteins if maintained for longer than 28 days in vitro. It may be that this phenotype appears after the observed changes in tau and $A \beta$ in this culture system.

It should be stated whether the 3xTg-AD mice used in this study are homozygous or heterozygous (I am presuming homozygous but this is not explicitly stated). It appears that the wild-type mice used as controls for the 3xTg-AD are background-matched, but not littermates. This is standard practice for many homozygous mouse lines but care should be taken to ensure backcrossing of the two lines to prevent genetic drift between colonies that have remained separated for a long time. Ideally, littermates would be used, but I understand that the homozygosity of this mouse model would complicate this and result in a greater number of animals being required to generate all genotypes. If separate colonies for transgenic and wild type pups are necessary, litters should ideally be synchronised to control for minor differences in culture preparation/ harvesting on different days.

\section{Are a suitable application and appropriate end-users identified?}

Yes 
If applicable, is the statistical analysis and its interpretation appropriate?

Yes

Are the 3Rs implications of the work described accurately?

Yes

Is the rationale for developing the new method (or application) clearly explained?

Yes

Is the description of the method technically sound?

Yes

Are sufficient details provided to allow replication of the method development and its use by others?

Yes

If any results are presented, are all the source data underlying the results available to ensure full reproducibility?

Yes

Are the conclusions about the method and its performance adequately supported by the findings presented in the article?

Yes

Competing Interests: No competing interests were disclosed.

Reviewer Expertise: Organotypic hippocampal slice cultures, Alzheimer's Disease

I confirm that I have read this submission and believe that I have an appropriate level of expertise to confirm that it is of an acceptable scientific standard.

\section{Comments on this article}

\section{Version 1}

Author Response 18 Jun 2018

Wendy Noble

We thank the reviewers for their balanced and critical reviews. We have responded to their comments point-by-point, below. A revised manuscript has also been submitted that clarifies/addresses these points.

Referee Report 29 May 2018 


\section{Susan C. Barnett, Institute of Infection, Immunity and Inflammation, College of Medical, Veterinary and Life Sciences, University of Glasgow, Glasgow, UK}

\section{Minor points:}

It would be very helpful to have a little more justification of why this is a novel method when many publications can be seen using slice cultures for Alzheimer's research, even from transgenic mice. We agree with this comment from the reviewer that others have published results using organotypic slice cultures, mostly limited to the hippocampus, from a range of Alzheimer's-relevant transgenic lines, particularly those expressing either human APP or tau. We cite several of these papers in the current manuscript.

This publication addresses a current gap in published descriptions of the full methodology used to produce organotypic cultures containing the hippocampus and cortex. We have already published twice with this method (Croft et al., 2017a, Croft et al., 2017b) and attribute the novelty of this system to our comparison of the development of pathological features in slice cultures and mice. We also show the utility of these slice cultures for identifying novel disease features and novel disease-modifying properties of compounds. We do not intend to suggest that our system is necessary a better model for investigating $A D$ - the mouse line that is used will be dependent upon the specific question under investigation. However, the methods we describe can be applied to any mouse line.

It was a little bit confusing on the section stating: In brief, slice cultures are cut whilst still on their membranes and then treated as free-floating sections. Is this illustrated in Figure 1? If so could be made clearer?

Figure 1 describes only the preparation of the slice cultures, prior to their culture. The statement mentioned is with regards to immunohistochemical staining which is described in full in a methods paper by others (Gogolla et al., 2006). Essentially, to avoid disruption to the tissue during its mechanical separation from insert membranes, the membranes are cut and sections with membranes adhering to their bottom surface are processed as for free-floating sections.

Not convinced the $\mathrm{n}=12$ from one pup statement is correct, as this would be replicates. $\mathrm{N}$ usually refers to different biological repeats.

The $n=12$ refers to the fact that 36 slices can be obtained from a single postnatal mouse brain. If, as commonly occurs, slices are plated 3 per well, this yields 12 wells of slices. If slices from several pups are plated in parallel, it is possible that each well could be analysed in relation to the corresponding wells from other pups. For example, either 12 time-points or 12 compounds can be examined in slices prepared from a single mouse.

It would be really useful to see example of the slices when validated, with examples of staining. Can microglia be seen and how good is the anatomy of the slices.

Numerous previous publications including Stoppini et al. (1991), Bahr et al. (1995), and De Simoni et al. (2006) have published detailed images showing the structural integrity of slice cultures. More recently, live microglial dynamics in slice cultures have been examined by Dailey et al. (2011). This was out-with the scope of the current publication, but we have added details of these papers to our manuscript to direct the reader to these complementary publications. 
The LDH was not explained enough and perhaps the time course could have been shown. We have previously described the methods and results obtained using LDH assays (Croft et al., 2017b), To avoid unnecessary duplication, this paper is focussed principally on the detailed methodology used to prepare organotypic cultures.

\section{Referee Report 22 May 2018}

Christian Humpel, Laboratory of Psychiatry and Experimental Alzheimer's Research, Medical University of Innsbruck, Innsbruck, Austria

Please provide more details in the Abstract, especially, on the organotypic brain slice model ( $3 x \mathrm{Tg}$ mice, chopper slices, $350 \mu \mathrm{m}$, postnatal d8-9, cultured for $>2$ weeks on $0.4 \mu \mathrm{m}$ pore semipermeable membranes). Please also add this information in the Box research highlights. This is important to see on one view which kind of slices you mean. We agree that this is a useful addition to the manuscript and have added this information to the revised paper.

I suggest that you are more careful about the used number of animals. In Abstract you write an estimated 20,000 mice per year for dementia research and on page 3, right col. sec. paragr. you write ... were used in AD research, and you write 20,000 transgenic; assuming from 30 mice per paper. What do you mean: (1) per year in UK, Europe or the world?, (2) total mice per year or only transgenic per year? (3) based on which fact you assume 30 mice per paper (value 30 is just your thoughts or is this based on an official reference?). I suggest that you check an EU report on the total number of animals/mice/transgenic, or you check your national institution (and also give the official reference). Such rough values could be very problematic. As we describe in the introduction, the number of 20,000 mice that we cite in the paper was calculated on the basis of a Pubmed search using the search terms "Alzheimer's + transgenic + mouse" in 2017. The results of this search are not limited to a single geographical location, so take into account world-wide publications. Sampling of these papers allowed us to estimate an average number of 30 transgenic plus non-transgenic mice per paper; where some use over 100, others use less than 12. It would be very useful to obtain official statistics on animal use, but the methods for collecting this data vary widely by regulatory authority. For example, in the UK, transgenic and wildtype mice subjected to regulated procedures are counted, but wild-type killed using Schedule 1 methods are generally not. We acknowledge that the numbers we cite are only an estimate and have modified the wording of this section to clarify this further. We believe that our estimate is very conservative and that actual animal usage is likely to be higher.

Page 3 third paragr: .... importantly, slice cultures are prepared from neonatal mice ... this (neonatal) should be explained as it is unclear.

We have made an addition to the manuscript to better explain that the use of neonatal mice is important because it precludes the ageing of mice with neurodegenerative phenotypes, removes the need to age numerous mice and requires only the maintenance of small breeding colonies for both cost and animal savings. We clarify elsewhere that we are referring to postnatal day (P) 8-9, but others have reported the same methods to prepare slice cultures form slightly older mice (P1012; Duff et al., 2001).

It would be helpful to give the average weight of the postnatal d8-9 mice. We usually weigh them, 
to be sure about the stage. Or do you have other rules to be sure on the correct stage. Also mention up to which age does your model work?

Mice were time-mated and checked every day to first confirm pregnancy and subsequently to check for the delivery of pups. The first day pups were found was marked as p0; p8-9

corresponding to 8 or 9 days from this time. In our hands, weighing the mouse pups was less consistent since this often corresponds to litter size and can vary with genotype. We therefore recommend preparing slices from $\mathrm{p} 8$ or $\mathrm{p} 9$ mice, which allows a time window to compensate for the lack of accuracy of recording birth time. We have previously prepared slices up to p12 (Duff et al., 2002), but with a different transgenic line which suggests that there may be variability between colonies. Slice cultures were also successfully prepared from p6 or p7 mice, although less slices per pup are obtained at these ages.

Page 5, point 6: typo: $2 x$ remove

This has been corrected, thank you.

Page 7 right col, last paragr: .... when reporting on the phosphorylation of tau via LiCl and GSK-3, the authors may cite the recent paper Foidl and Humpel (2018) in Frontiers Aging Neurosci. on hyperphosphorylation of tau in organotypic brain slices induced by okadaic acid. In this respect also the review on brain culture slices by Humpel (2015) in Neuroscience should be cited (page 4, left col, line, 14).

Thank you for these suggestions. We have added these papers to the revised manuscript.

Please explain better your definition of the n-number (page 8 , right col.) .... one postnatal d8 or 9 pup can provide an $n=36$. I think that one mouse only gives an $n=1$; for an experiment you need at least 6-8 different mice ( $n=6-8$ ); but one mouse can give up to 36 different treatments (or in duplicate $2 \times 18$ ). What is your suggestion on power calculations (how many slices per group?). Please explain better any statistical issues.

We agree that slices prepared from one mouse are equivalent to $N=1$. The $n=12$ refers to the fact that 36 slices can be obtained from a single postnatal mouse brain. If, as commonly occurs, slices are plated 3 per well, this yields 12 wells of slices. If slices from several pups are plated in parallel, it is possible that each well could be analysed in relation to the corresponding wells from other pups. For example, either 12 time-points or 12 compounds can be examined in slices prepared from a single mouse.

We used data generated from our previous work with post-mortem brain and brain slice cultures to perform power calculations. These calculations show that at a $5 \%$ significance level and a statistical power of $90 \%$ to show $25-30 \%$ differences between groups, for most experiments, we require sample sizes of $n=6$ for slice culture work. All brain slice culture experiments will include experimental triplicates to improve robustness and reproducibility of our findings.

Finally, please state in your conclusion the limits of the brain slices; how to study genetic (familiar) versus sporadic $A D$, how comparable is the developmental stage with the adult stage (maturation of neurons after 2 weeks in culture?), how long do you need to culture to get at least an early comparable adult stage, what about axonal networks and the problem of axotomy. We already discuss the equivalent times in culture versus in vivo for the neurodegenerative phenotypes being studied in this work (Table 1). We are unable to comment knowledgeably on the equivalent developmental stages in slices compared to in vivo, and this is somewhat outside the 
scope of this methods paper.

We agree that it is a good idea to further discuss some of the limitations of this system, including the lack of vasculature, the problems with axotomy and loss of innervation, layer of reactive astrocytes and flattening/thinning of the slice cultures over time. We have therefore revised the manuscript to include additional discussion. In terms of sporadic versus familiar $A D$, it is acknowledged that studying sporadic $A D$ is a universal problem in the field but the pathophysiological similarities between familial and sporadic AD suggests that familial models have utility. For example, recent work from the expansive DIAN-TU study highlights the similar progression and overlapping pathology between sporadic and familial $A D$, which further supports the use of familial models to understand sporadic AD (https://www.alzforum.org/news/conferencecoverage/dian-and-adni-data-say-familial-and-sporadic-ad-converge).

\section{Referee Report 18 May 2018}

Claire S. Durrant, John van Geest Centre for Brain Repair, Department of Clinical Neurosciences, University of Cambridge, Cambridge, UK

Minor comments:

Whilst actin is a valid control protein in western blots, it could be argued that beta-III tubulin (or alternative neuronal markers) may be a more informative control when normalising synaptic protein levels. This controls for any difference in neuronal number between samples which may alter synaptic protein levels in the absence of a synaptic specific change. This would be more important in cases where synaptic protein levels are down, but there is also evidence for neuronal $\underline{\text { loss. }}$

We appreciate this comment and agree that normalising synaptic proteins to a measure of neuron number is important to identify changes in global synaptic protein amounts in total lysates. Since we do not see any overt neuron loss in the slices (at least up to 28 DIV), we were interested in understanding some of the changes that occur at synapses prior to neuron loss. The synaptosome preparation isolates the synaptic compartment of slices, and therefore allows analysis of protein changes specifically within surviving synapses. In these experiments, it is not necessary to also take into account measures of neuron numbers.

It would be interesting to see whether the 3xTg-AD brain slices lose synaptic proteins if maintained for longer than 28 days in vitro. It may be that this phenotype appears after the observed changes in tau and $A \beta$ in this culture system.

We agree that these are important experiments to do, and would be in-keeping with data from your group and others who show loss of pre-synaptic proteins alongside increased Abeta production. We do not have any data on this at the current time.

It should be stated whether the 3xTg-AD mice used in this study are homozygous or heterozygous (I am presuming homozygous but this is not explicitly stated). It appears that the wild-type mice used as controls for the 3xTg-AD are background-matched, but not littermates. This is standard practice for many homozygous mouse lines but care should be taken to ensure backcrossing of the two lines to prevent genetic drift between colonies that have remained separated for a long time. Ideally, littermates would be used, but I understand that the homozygosity of this mouse model would complicate this and result in a greater number of animals being required to generate all genotypes. If separate colonies for transgenic and wild type pups are necessary, litters should 
ideally be synchronised to control for minor differences in culture preparation/ harvesting on different days.

We also agree with this comment. The 3xTg-AD mice were homozygotes. They and their nontransgenic counterparts were obtained after they had been re-derived and backcrossed to minimize genetic drift. Genotyping was performed regularly (every generation) on our colony to ensure that transgene expression was consistent since we are aware that this can be a problem with transgenic lines. Litters from 3xTg-AD and non-transgenic background mice were time-mated and synchronised to minimize batch differences. Slice cultures used to compare directly between genotypes were prepared with the same reagents within 24 hours of their age-matched counterparts. We agree that littermate controls are more desirable, but we were unable to do this for the reported work.

Competing Interests: No competing interests were disclosed.

The benefits of publishing with F1000Research:

- Your article is published within days, with no editorial bias

- You can publish traditional articles, null/negative results, case reports, data notes and more

- The peer review process is transparent and collaborative

- Your article is indexed in PubMed after passing peer review

- Dedicated customer support at every stage

For pre-submission enquiries, contact research@f1000.com 